\title{
Percepção do tempo em ficções projetuais contemporâneas
}

\section{Perception of time in contemporary design fictions}

ZMIEVSKI, Eduardo; Graduando; Universidade Federal do Paraná, UFPR, Brasil. zmievski.eduardo@gmail.com

VAN AMSTEL, Frederick M. C.; Doutorado em Design; University of Twente, UT, Holanda. usabilidoido@gmail.com

BECCARI, M. N.; Doutorado em Educação; Universidade de São Paulo, USP, Brasil. contato@marcosbeccari.com

\section{Resumo}

Este artigo propõe esclarecer as principais características do gênero da ficção projetual através da análise obras contemporâneas que abordam diretamente a questão da percepção do tempo, e também verificar a capacidade do design especulativo como método de projeto. Como base da análise foi realizada uma revisão bibliográfica sobre ficção projetual, design especulativo e percepção temporal. A partir desta revisão, foram extraídos os critérios de seleção das amostras bem como os pontos de análise a serem observados. Após a análise se conclui que a ficção científica coloca a percepção do tempo como uma questão social, enquanto a ficção projetual coloca o tempo como uma questão de design. Também conclui-se que existem diferentes abordagens para lidar com a percepção do tempo num projeto de design especulativo, e a ficção projetual é uma maneira do design propor reflexões sobre o papel do tempo na sociedade mais ativamente.

Palavras Chave: ficção projetual; design especulativo; percepção temporal.

\section{Abstract}

This article proposes to clarify the main characteristics of the genre of design fiction through the analysis of contemporary works that directly address the question of the time perception, and also verify the ability of speculative design as a design method. As a basis for the analysis, a bibliographic review was carried out on projective fiction, speculative design and temporal perception. From this review, the selection criteria of the samples were extracted as well as the points of analysis to be observed. After the analysis we conclude that science fiction places the perception of time as a social issue, while the projective fiction puts the time as a matter of design. It also concludes that there are different approaches to dealing with the perception of time in a speculative design project, and design fiction is a way for design to propose reflections on the role of time in society more actively.

Keywords: design fiction; speculative design; time perception. 


\section{Índice}

1. Ficções Projetuais

\subsection{Speculative Design}

2. Percepção temporal de Design

3. Análise: Percepção do tempo em ficções

3.1. "In Time", 2011

3.2. "Voxel", 2017

4. Conclusão

\section{Ficções Projetuais}

Design Fiction (BLEECKER, 2009) ou, em português, Ficções Projetuais (VAN AMSTEL, 2015) é um gênero de projeto que especula sobre um possível futuro próximo da sociedade considerando determinadas circunstâncias e contextos através da tecnologia. O gênero pode ser considerado uma derivação da Ficção Científica, porém, se diferencia dela por ter um propósito distinto do entretenimento. A Ficção Projetual pode ser usada como um método de pesquisa de design a fim de criar ações no presente que influenciarão o futuro e a interpretação do passado, sendo portanto considerados projetos de caráter ideológico (GONZATTO; VAN AMSTEL; MERKLE e HARTMANN, 2013).

Uma ficção projetual consiste em especular futuras possibilidades, ideias e soluções dentro de cenários e circunstâncias específicas acerca de uma tecnologia emergente. Mas qual a diferença disso para um projeto de design "comum", como projetar uma cadeira ou um livro? O que difere, entretanto, a ficção projetual de um "projeto comum" de design é seu caráter de pesquisa experimental com foco nas interações cotidianas com a tecnologia. Ao invés de se preocupar com detalhes técnicos de forma, estrutura ou função do objeto, ficção projetual lida com o uso do objeto no cotidiano, mesmo que ainda não haja uma tecnologia viável para aquele uso.

Apesar de explorar formatos clássicos da Ficção Científica, tais como o curtametragem, a revista em quadrinhos e o livro, o gênero de ficção projetual se esforça em distinguir-se da Ficção Científica.

"O ponto da ficção projetual é mostrar um cenário factível para o futuro próximo da sociedade. A distância desse cenário futuro é um projeto, ou seja, o conhecimento científico e a tecnologia necessária para sua realização já se encontram disponíveis ou estão em vias de serem disponibilizadas. Essa é também uma diferença fundamental com a ficção científica, que focaliza nos possíveis avanços da ciência em futuros mais distantes. A ficção projetual é sobre o futuro próximo, em geral, 10 anos daqui pra frente. O cenário focaliza nas mudanças no dia-a-dia de pessoas comuns e não em aventuras de heróis." (VAN AMSTEL, 2015, s.p.).

Um bom exemplo para ilustrar esta diferença é tomarmos as obras literárias de Isaac Asimov, tais como A Fundação ou Eu, robô?, escritas no início do século XX, quando as idéias e tecnologias para a materialização da realidade por ele propostas eram absurdas. Dado o contexto histórico, tecnológico e sócio-cultural da época, as obras de Asimov eram vistas como delírios futurólogos sem uma ligação com o dia-a-dia das pessoas comuns, por isso foram chamadas de Ficção Científica. Em contraste o seriado 
televisivo Black Mirror do contemporâneo Charlie Brooker apresentam histórias cujas a tecnologias e ideias já existem atualmente ou estão muito próximos de existir. 0 que Brooker propõe em suas ficções são cenários de como certas tecnologias emergentes podem afetar negativamente o comportamento humano. Em Black Mirror, a tecnologia é um meio para se abordar criticamente padrões de comportamento culturais, tais como relacionamentos, moral, política, ética, sentimentos e privacidade. Devido a essa aproximação com a realidade, a maior parte dos episódios de Black Mirror podem ser consideradas Ficções Projetuais. Esse tipo de ficção distingue-se das Ficções Científicas com tecnologias e cenários tão distantes da nossa realidade, que criam um abismo entre o dia-a-dia do humano que consome o produto de ficção e as aventuras fantásticas dos personagens da ficção.

Uma abordagem proposta para reduzir esta diferença entre o humano comum e o personagem da ficção é a produção de protótipos que simulam de algum modo a realidade proposta e tornam a experiência amanuável, um conceito criado pelo filósofo Álvaro Vieira Pinto, onde a realidade se torna disponível ao manuseá-la diretamente. Realidade é um processo, e está por natureza em constante mudança. Seres humanos estão embutidos na realidade, moldando-a e sendo moldados por ela (GONZATTO; AMSTEL; MERKLE e HARTMANN, 2013). Esta amanualidade pode se manifestar através da criação de "Props", como o mesmo autor sugere: "Tangíveis e materializados que vivem entre fato e ficção e são tanto especulativos quanto possíveis." (BLEECKER, 2010, Tradução nossa, s.p.) Formalmente chamados de Theatrical property, props é um termo original da cinematografia e teatro que se refere a objetos que servem de pivô para ações dos atores ou até mesmo que chegam a contracenar com os atores, adquirindo um papel mais importante do que o figurino e cenografia tradicional. Numa ficção projetual estes objetos dão forma e peso às idéias do projeto, e o processo dessa materialização já força a se considerar outras possibilidades que somente no papel não surgiriam tão facilmente. O conceito de Props de assemelha bastante ao de Protótipos diegéticos, cunhado por (KIRBY, 2009) que o define como representações cinematográficas de tecnologias futuras. São objetos reais no universo particular da narrativa com suas particularidades, limites e coerências determinadas pelo autor, fazendo sentido dentro da narrativa e estendendo a análise da utilidade desses protótipos virtuais. Os props numa ficção projetual possuem uma função distinta de uma produção de ficção científica, pois na primeira eles tem a função de materializar os conceitos do projeto e servem como interfaces para mediar a relação dos atores com a experiência porém sem o mesmo nível de detalhamento e apelo que um prop cinematográfico ou literário possui numa ficção científica. Eles também devem ter suas funções focadas nas atividades cotidianas dos atores de uma ficção projetual, convertendo o extraordinário e novo num objeto ordinário e comum dentro do universo da ficção, pois segundo (BLEECKER, 2009) são as ações comuns do dia-a-dia que se percebem essa incompletude e a ordinaridade desses objetos que geram as fricções entre o real e ficcional.

\subsection{Speculative Design}

O interesse de designers em projetos de ficção projetual levou Dunne \& Raby a formular uma abordagem de projeto focada no gênero chamada Design Especulativo. 0 termo foi cunhado no livro Speculative Everything: Design, Fiction and Social Dreaming (DUNNE \& RABY, 2013) onde os autores apresentam a ideia de usar o design como meio para imaginar como as coisas poderiam ser. Ele pode ser uma abordagem para produzir projetos desse gênero, pois se concentra no potencial da construção de cenários possíveis como fontes de discussão. Esta forma de imaginação pode servir para se 
explorar novas perspectivas sobre o que se conhece como Wicked problems (RITTEL \& WEBBER, 1973) - traduzidos como Problemas Capciosos, são aqueles que não possuem uma solução ou meios para tal de forma clara, com requisitos mutáveis e interdependentes que dificultam ainda mais a identificação e solução dos mesmos - e criar espaços para discussão e debate sobre modos de ser alternativos, a fim de inspirar e encorajar a imaginação livre sobre o assunto. Para Dunne e Raby, o design especulativo tem potencial para redefinir nossa relação individual e coletiva com a realidade atual, e não está interessado em propor soluções ou predizer o futuro de forma objetiva. Pelo contrário, o ponto da especulação aqui é imaginar futuros possíveis e usá-los como ferramentas para compreender melhor o agora e discutir sobre os futuros que queremos e também aqueles que não queremos. A partir da criação de cenários, ou situações que geralmente começam com a pergunta "e se...?", é que se abre espaços para discussões e diálogos provocativos, intencionalmente simplificados e fictícios. A ficção aqui se faz necessária para que o público suspenda por alguns momentos sua incredulidade e permita sua imaginação divagar, esquecendo momentaneamente como as coisas são agora e pensar em como elas poderiam ser (DUNNE \& RABY, 2013).

A partir disso, os autores propõem um diagrama baseado na visita do futurologista Stuart Candy ao Royal College of Art em 2009 que ilustra os diferentes tipos de futuros possíveis através de cones, onde cada um representa em espectro os níveis de possibilidade (figura 1).

Figura 1 - PPPP

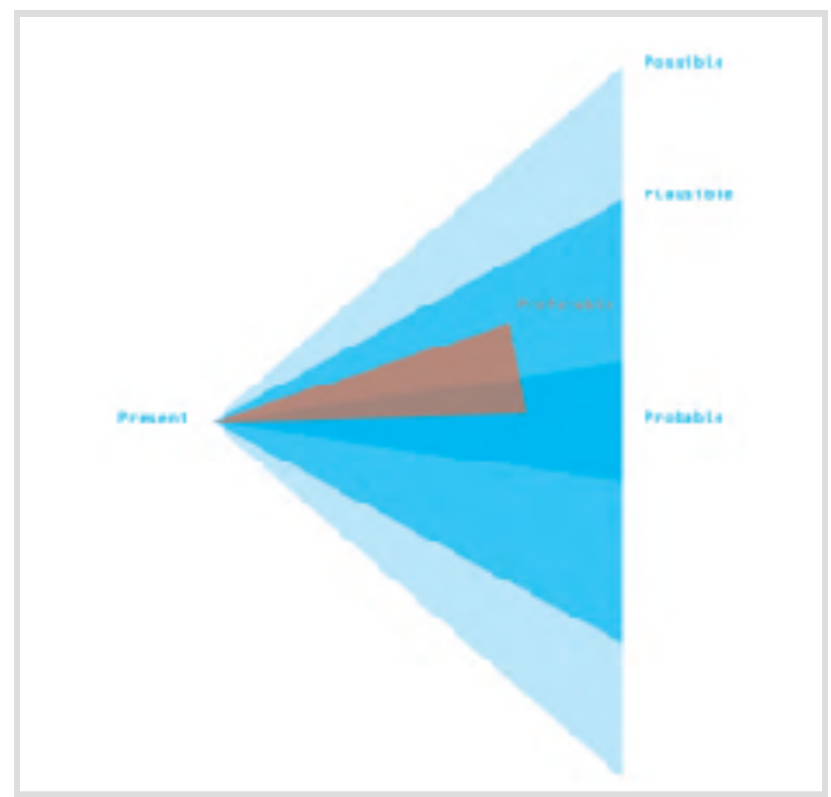

Fonte: Dunne \& Raby (2013)

O primeiro cone é o Provável, no qual a maior parte dos projetos comuns de design operam. Ele descreve o futuro possível sem considerar uma grande crise ou mudança de paradigmas, sendo o mais conservador. O próximo cone é o Plausível, onde se começa a esboçar possibilidades mais ousadas considerando situações menos prováveis, porém ainda possíveis dado o cenário atual. Seguinte é, o cone do Possível, no qual as mudanças e cenários são mais difíceis de se imaginar e principalmente vincular ao presente, ou como se chegou até lá a partir do agora. Ele trabalha com 
possibilidades remotas, científicas ou socialmente possíveis, porém sem apresentar um caminho plausível do percurso. Para além deste cone, os autores consideram a área da fantasia, que extrapola qualquer possibilidade de concretização e trabalha a uma distância do real e agora que não é interessante aqui e pertence ao sci-fi, contos de fadas e óperas cinematográficas. 0 design especulativo almeja trabalhar num espectro Preferível entre os cones do Provável e Plausível, que em primeiro lugar é cientificamente possível e em segundo lugar é possível traçar um caminho de onde estamos hoje até este futuro possível. Então se cria uma série de eventos críveis através ficções e permitindo aos espectadores relacionar-se com o cenário de seu mundo com a narrativa e proporcionar reflexões críticas acerca dela.

\section{Percepção temporal e Design}

Tomando a definição da ideia de tempo como uma construção humana se parte do princípio que ele pode ser projetado, e portanto também um possível tema de ficção projetual através de um projeto de design especulativo, tal como proposto por (WANG, 2015) em seu artigo "Tools for mindful timekeeping: 4 devices to change our relationship with time". A percepção do tempo para cada indivíduo pode variar drasticamente, uma vez que é influenciada por fatores internos e externos ao indivíduo, tais como estados emocionais e psicológicos, condições físicas e de saúde ou situações de estresse ou prazer. Além da variação individual, existe também a variação coletiva causada por agentes naturais, ciclos dos astros, estações, marés e o contexto social e histórico (HAMMOND, 2013). Como exemplo, podemos observar uma grande aceleração da passagem do tempo em nível global com o avanço da industrialização e comércio no século XIX, quando objetos como o relógio esboçaram os primeiros modelos de controle social e serviram como mediadores das relações entre empregados/patrões que hoje vemos refletidos por exemplo, em nossa rotina de sono/vigília e trabalho/lazer: ambas estão pautadas sob os ritmos de produção industrial e consumo capitalista.

A padronização do tempo pretende determinar o modo que o percebemos criando expectativas sobre como experienciamos determinadas situações. A padronização temporal é uma ferramenta para determinar como devem ser estas experiências e assim gerar um sistema de controle universal que quantifica, organiza e gerencia o tempo conforme os interesses do próprio sistema em prol de sua manutenção. Entretanto, apesar dessas medidas de colonização do tempo, e consequentemente de produção de uma rotina, coexistem práticas sociais e culturais que desviam, rejeitam ou ressignificam a o tempo industrial.

Algumas tentativas de padronização do tempo produziram numa relação dialética objetos de design, tendo um exemplo básico no relógio. Basta observarmos a predominância desse objeto em nossa rotina: desde o topo da torre do Big Ben, passando pelo relógio de parede, de bolso e posteriormente de pulso até nossos atuais marcadores digitais, a influência onipresente desse mecanismo de controle se manifesta em diversos outros objetos como calendários, agendas, e de formas imateriais como rotina e o fuso horário. Apesar da tentativa de estabelecer padrões de percepção do tempo através destes mecanismos, nossa percepção de tempo não é uniforme. Isto porque o tempo é percebido através da memória, pois tudo que é experienciável só existe de fato somente no momento presente. Assim que esse momento passa, somente uma lembrança dessa memória pode reconstruir essa experiência, e o modo como guardamos está ligado diretamente a interpretação e emoções subjetivas que distorcem tempo e o modo como essa memória será reconstruída. Esta lembrança é construída subjetivamente por cada 
indivíduo - ou no caso de grupos, da memória coletiva - e portanto está sujeita a distorções devido a influência de diversos fatores como idade, drogas, estado emocional e até temperatura corporal.

Estas capacidades porém, podem ser manipuladas como já citado devido a estarem intimamente ligadas a fatores externos e subjetivos mas também pela interação com objetos de design. 0 texto "Temporal design: looking at time as social coordination" (PSCHETZ L., BASTIAN M. \& SPEED C. 2016) propõe que há diferentes abordagens de design sobre o tempo, como o Slow Design (STRAUSS \& FUAD-LUKE, 2009) e Design for Solitude (FULLERTON, 2010). Dentre elas, os autores identificaram um crescente interesse pela especulação do futuro através de ações no presente, especialmente com o avanço de novas tecnologias. Entretanto essas abordagens são criticadas por (PSCHETZ L., BASTIAN M. \& SPEED C. 2016) por reforçar o discurso hegemônico do tempo padronizado universal e da crescente noção de aceleração do tempo devido aos avanços tecnológicos, ora soando como tentativas de uma volta ao passado através de técnicas de desaceleração do tempo como o apelo à atividades manuais (Slow Design), ora como redução da complexidade da temporalidade atual através da limitação de determinadas atividades com a intenção de reduzir a quantidade de informações e decisões a serem tomadas (Design for Solitude). Essas tentativas de retorno ao passado e redução de complexidade se negam a lidar com questões emergentes e podem ser compreendidas como um escapismo e negligência da realidade.

Por isso, (PSCHETZ L., BASTIAN M. \& SPEED C. 2016) propõem uma perspectiva diferente para encarar a temporalidade e consequentemente a complexidade intrínseca que envolve tanto fatores internos e pessoais quanto externos e sociais. Ao invés de focar no design como ritmo de tempo ou especulações sobre o futuro, elas e ele propõem uma visão mais ampla que considere o papel do tempo como coordenador social, e como ele molda a interação social de indivíduos e grupos sociais: o Design Temporal. Em vez de compreender o tempo como um agente externo, objetivo e imparcial, a proposta do Temporal Design é justamente encarar a subjetividade e assumir que temporalidade é uma construção humana e social, e que através dela podemos identificar a rede de temporalidades, mecanismos de dominância e narrativas dominantes, e empoderar discussões sobre as mesmas e desenvolver noções alternativas do tempo em prol da colaboração social.

Como exemplo de Temporal Design, Os mesmos autores propõe projetos que colocam em prática essa abordagem, um deles é o "Family Clock" [figura 2]. O projeto consiste num sistema que representada fisicamente um relógio que apresenta a duração de um dia invés das horas, e controla o tempo conforme os compromissos familiares que cada membro insere através de um aplicativo. A passagem do tempo e a velocidade do ponteiro, bem como a interface do aplicativo mudam e se adaptam às mudanças de compromissos que cada membro da família insere, a fim de que todos estejam no mesmo ritmo e consigam manter sua rotina sincronizada. 0 projeto foi testado com três famílias americanas, pelo período de três semanas, onde foram solicitados para interagir com o sistema e seguidos de entrevistas pelos pesquisadores. 
Figura 2 - Family Clock
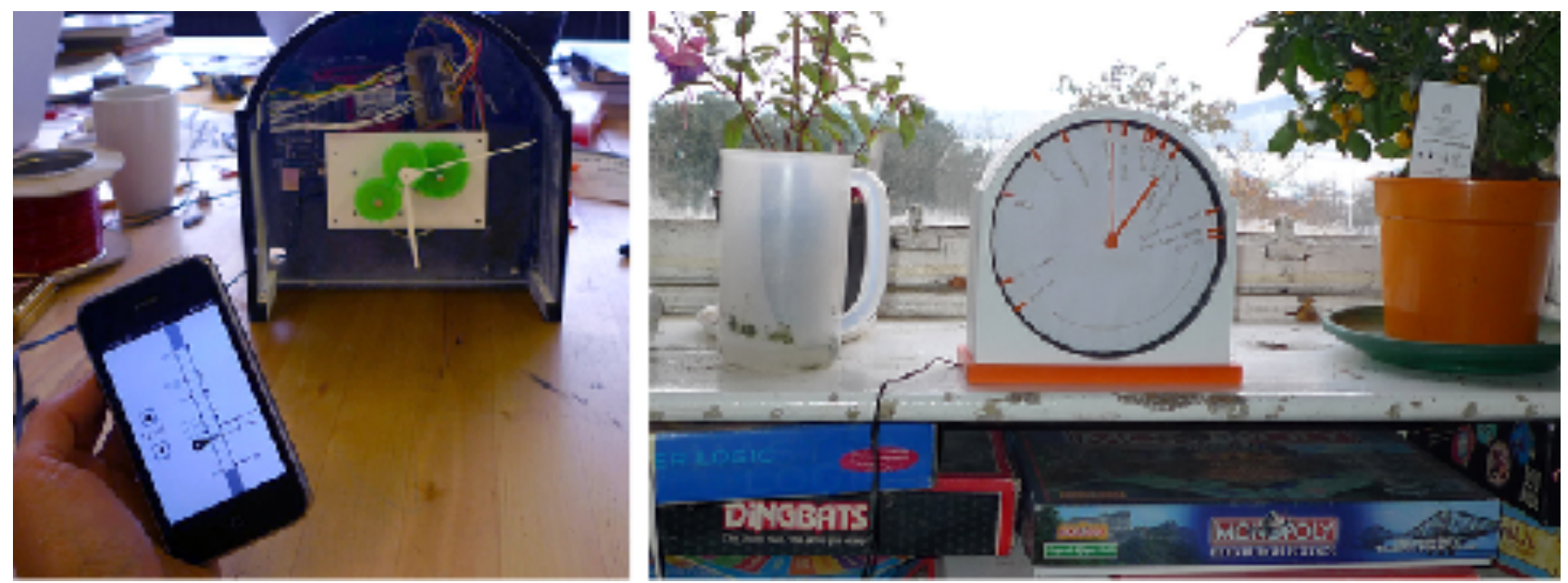

Fonte: (PSCHETZ L., BASTIAN M. \& SPEED C. 2016)

\section{Análise: A percepção do tempo em ficções}

A fim de verificar quais diferenças podem ser percebidas entre ficção científica e ficção projetual na maneira como representam a percepção do tempo com base nos conceitos apresentados anteriormente, bem como acerca da capacidade da ficção projetual como gênero e da ficção projetual como abordagem de projeto, foram analisadas duas obras contemporâneas de ficção selecionadas especificamente porque abordam a questão da percepção temporal diretamente dentro dos gêneros de ficção projetual ou ficção científica. São elas o longa metragem "In Time", 2011 ("O preço do amanhã") e o projeto "Voxel", (2017). O objetivo dessa análise é identificar o modo que a percepção temporal é representada, os mecanismos que a operam e como isso ocorre e, a partir disso verificar as características de cada uma sob os pontos de análise a seguir conforme as definições propostas pelos autores correspondentes.

Tabela 1 - Critérios de Seleção de amostras

\begin{tabular}{|c|c|}
\hline Gênero Cinematográfico & Referências \\
\hline $\begin{array}{c}\text { A obra pode ser considerada ficção projetual } \\
\text { ou ficção científica? }\end{array}$ & $\begin{array}{c}\text { (BLEECKER, 2009) } \\
\text { (DUNNER \& RABY, 2013) } \\
\text { (VAN AMSTEL, 2015) }\end{array}$ \\
\hline
\end{tabular}

Fonte: O Autor 
Tabela 2 - Critérios de Seleção de amostras

\begin{tabular}{|c|c|c|}
\hline Ponto de análise & Descrição & Referências \\
\hline $\begin{array}{l}\text { 1. Características } \\
\text { de design do Prop }\end{array}$ & $\begin{array}{l}\text { Objetos utilizados como pivô } \\
\text { para ações de atores }\end{array}$ & (BLEECKER, 2010) \\
\hline $\begin{array}{l}\text { 2. Relação entre Prop } \\
\text { e Narrativa }\end{array}$ & $\begin{array}{l}\text { Recursos de Design para mediar } \\
\text { a percepção do tempo }\end{array}$ & (KIRBY,2009) \\
\hline $\begin{array}{l}\text { 3. Abordagens de design } \\
\text { sobre o tempo }\end{array}$ & $\begin{array}{l}\text { Proposta pela qual o design molda a } \\
\text { percepção de tempo dos personagens }\end{array}$ & $\begin{array}{c}\text { Slow Design } \\
\text { (STRAUSS \& FUAD-LUKE, 2009) } \\
\text { Design for Solitude } \\
\text { (FULLERTON, 2010) } \\
\text { Temporal Design } \\
\text { (PSCHETZ L., BASTIAN M. \& } \\
\text { Â SPEED C. 2016) }\end{array}$ \\
\hline $\begin{array}{l}\text { 5. Percepção do tempo dos } \\
\text { personagens }\end{array}$ & $\begin{array}{l}\text { Como os personagens são } \\
\text { influenciados pela abordagem de } \\
\text { design e pelos props }\end{array}$ & (HAMMOND, 2013) \\
\hline
\end{tabular}

Fonte: O Autor

\section{1. "In Time", 2011}

Num futuro onde as pessoas param de envelhecer aos 25 anos, mas são geneticamente modificadas para viver apenas mais um ano tendo que encontrar maneiras para comprar a saída dessa situação e permanecerem imortais, o tempo é a moeda de troca universal e as zonas horárias o sistema de castas que separa os ricos dos pobres. Neste cenário, o personagem Will Salas se encontra acusado de um assassinato e roubo de tempo e foge com a refém Sylvia Weiss e juntos começam uma campanha contra o sistema que mantém o privilégio de tempo dos poucos ricos imortais em detrimento da morte de muito pobres marginalizados.

\subsubsection{Características dos Props}

$\mathrm{Na}$ obra, o dispositivo de controle do tempo se chama "relógio" e consiste num cronômetro sob a pele do braço esquerdo, que ao ser ativado aos 25 anos de idade começa uma contagem regressiva do tempo de vida restante do usuário. No filme, em nenhum momento se explicita como essa tecnologia veio a ser possível, o quão distante esse futuro é da nossa atualidade e tampouco o seu funcionamento. 
Figura 3 - Interação entre usuários

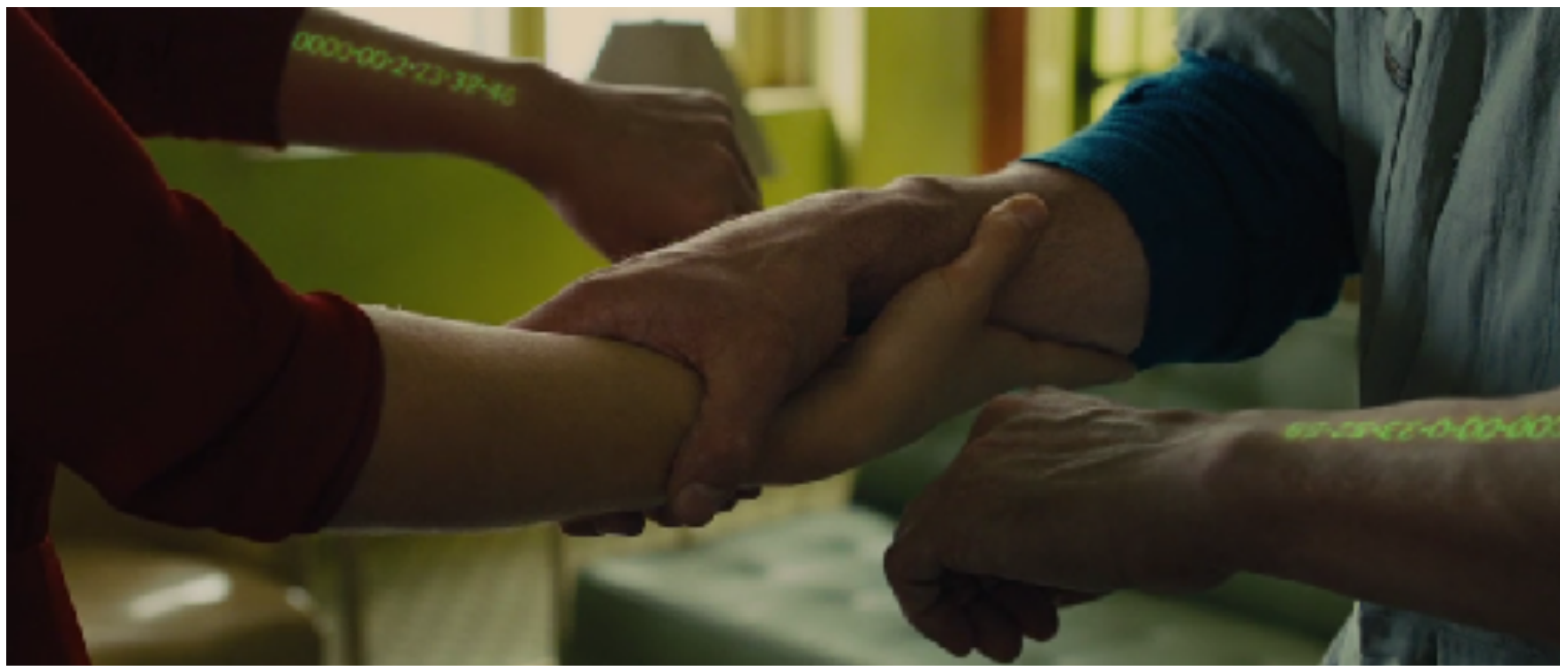

Fonte: O Preço do amanhã (2011)

Os usuários podem compartilhar seu tempo com outros através de um gesto similar ao aperto de mão, e transferir seu tempo uns aos outros (figura 3). Para efetuar compras ou receber pagamentos, há um objeto de metal que se assemelha à uma máquina de cartão de crédito que, ao ser aproximada do braço direito do usuário, realiza as transações (figura 4). Alguns personagens também "lutam" por mais tempo numa espécie de queda de braço onde o vencedor leva o tempo de vida do derrotado.

Figura 4 - Dispositivo de cobrança e pagamentos

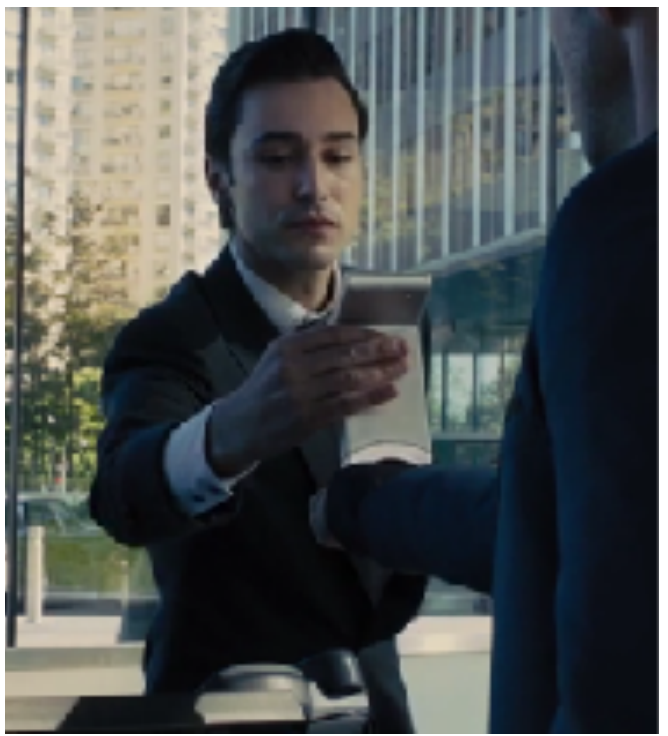

Fonte: O Preço do Amanhã (2011)

\subsubsection{Relação entre Prop e narrativa}

Percebe-se que todo o ambiente urbano foi modificado para abarcar uma população sempre jovem e saudável, porém com divisões claras através de fronteiras 
que dividem o espaço de ricos e pobres através das zonas de tempo. A arquitetura e os artefatos como carros e decoração, principalmente dos mais abastados, possuem uma estética mais antiga, mesmo com tecnologia de ponta em seu interior, o que provavelmente representa um status social mais elevado: aquilo que parece mais antigo, custa muito mais tempo. 0 pedágio para deslocamento entre zonas de tempo também é uma barreira para limitar o acesso às áreas mais abastadas, bem como o custo de vida se torna cada vez mais elevado conforme se avança nas zonas temporais. Os indivíduos em zonas marginalizadas tendem a agir de forma mais cautelosa e individualista em relação aos demais, por terem receio de terem seu pouco tempo tirado de si. Também os mesmos adiam atividades de lazer em prol do trabalho, pois estão sempre com pouco tempo de sobra e, se entram em dívidas, os juros de empréstimos são altíssimos, sendo comum nestas zonas encontrar corpos de trabalhadores mortos que não conseguiram ganhar mais tempo.

\subsubsection{Abordagem de Design}

"In Time" apresenta em sua narrativa uma abordagem da aceleração da percepção e hipérbole dos mecanismos de padronização e controle do tempo, e não se enquadra em nenhum das abordagens anteriormente propostas para modificar a percepção do tempo. 0 dinheiro que atua como metáfora de tempo em nossa realidade, foi abolido a fim de expor literalmente o atual sistema socioeconômico e suas consequências. Não foi possível identificar na obra as características de abordagens como Slow Design, Design for Solitude ou Temporal design, deixando clara a não intencionalidade da mesma em propor uma abordagem de design acerca do tema, mas propõe uma solução óbvia e ineficiente que não deixa brechas para discussões, servindo apenas como resolução para a trama da narrativa.

\subsubsection{Tipo de Ficção}

A obra não pode ser considerada uma ficção projetual, pois o foco da obra está no entretenimento e na narrativa do herói, e não em levantar discussões sobre o tema, explorar idéias sobre interações entre usuários - ainda que possa fazer isso em segundo plano - e porque principalmente, não há uma especulação sobre futuros próximos e as implicações em comportamento, sociedade e tecnologia. Também se observou que os props aqui servem à narrativa somente como reforço visual, e mesmo que proponham interfaces e interações interessantes, seu objetivo é secundário. A narrativa não está focada nessas interações mas na trama, coisa que numa ficção projetual serve para ambientar as interações que são o tema principal. O problema da trama não é discutido a fundo, e serve apenas como pretexto narrativo para conclusão rápida da história, e o debate crítico acerca do tema, das interações ou dos objetos é deixado de lado em detrimento da função narrativa. Por fim, a obra não especula sobre um futuro próximo, mas propõe uma ficção que apesar de questionar o status quo através do exagero da realidade, durante toda a obra nega a tecnologia invés de usá-la como um meio para transformar o presente. No caso de uma ficção projetual, os próprios artefatos demonstrariam a contradição e permitiriam brechas para discussão e propor mudanças.

\subsubsection{Percepção do tempo dos personagens}

O personagem de Will trabalha numa fábrica desse dispositivo e, assim como todas as pessoas em sua "zona de tempo", recebe um salário muito pequeno que os faz criar hábitos particulares como estar sempre olhando para seu relógio e conferindo seu tempo restante, correndo para realizar as atividades de seu dia sempre com pressa, 
devido ao pouco tempo que possuem para gastar e não poderem se dar ao luxo de interações e atividades mais lentas. Já os mais abastados possuem hábitos menos agitados e sua relação com as atividades e o tempo tende a ser menos preocupada. 0 ritmo de suas vidas é representado de forma mais lenta, quase monótona. As atividades físicas que envolvem riscos são consideradas perigosas e, quanto mais rico o sujeito, mais meios para se manter seguro ele possui, como seguranças particulares e reservas de tempo em cofres. Na trama, um dos personagens que já viveu mais de cem anos questiona o sistema que perpetua a vida humana e seu desbalanceamento com os recursos naturais necessários para manter toda a população imortal, sendo o sistema de castas a solução imposta pelos ricos para se manterem imortais.

\section{2. "Voxel", 2017}

Num contexto atual, o uso de computadores como ferramenta de trabalho somado à grande quantidade de opções de entretenimento, distrações e informações de todos os tipos que lidamos diariamente tendem a tirar nosso foco facilmente daquilo que realmente deveríamos fazer e boa parte do tempo é gasto em procrastinação, o que se torna um grande problema para muitas pessoas que não conseguem cumprir suas demandas. Propondo uma discussão especulativa para este problema, Saito, Juliana Hiromi. desenvolveu o projeto Voxel: Assistente digital para lidar com a procrastinação (Trabalho de Conclusão de Curso). Design Digital, PUCPR, 2016. um assistente digital para organização de tarefas criado para evitar a procrastinação. A idéia do projeto surgiu justamente enquanto a autora procrastinava o seu trabalho de conclusão de curso e este veio a ser o tema do trabalho final.

\subsubsection{Características do Prop}

O objeto se apresenta como um pixel que ao observar o comportamento humano em frente ao computador e percebendo a dificuldade humana em realizar suas tarefas de maneira eficiente frente à quantidade de distrações que lhes são fornecidas o tempo todo. Então ele se materializou em forma de um cubo que emite luz, sons e vibrações conforme as atividades que o usuário está realizando em seu computador (figura 5). Mas sua inteligência artificial é o fator principal de seu funcionamento, é através dela que o software se conecta ao computador do usuário e tem acesso à todas as suas atividades em programas de computador, aplicativos, redes sociais e agenda organizando em níveis de prioridade as tarefas e limitando o acesso do usuário à atividades que tirem o foco da tarefa principal. 0 objeto se comunica com o usuário quando este está procrastinando pode bloquear a atividade temporariamente e requer que o mesmo execute alguma ação como manipular o objeto por alguns instantes para que ele libere novamente o uso da aplicação (figura 6). Ele também notifica o usuário em casos de tarefas urgentes e automatiza pequenas outras atividades, como responder emails automaticamente. 
Figura 5 - Prop Voxel

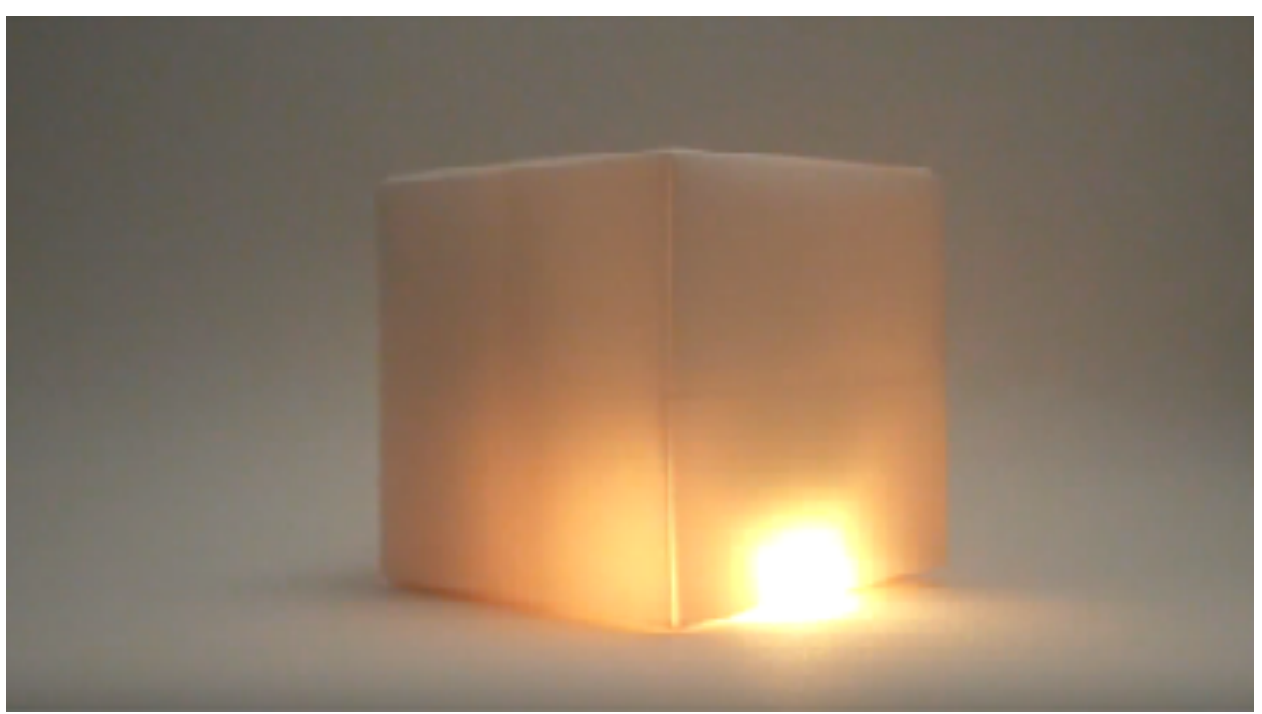

Fonte: Voxel (2017)

\subsubsection{Relação entre Prop e narrativa}

A ficção de Voxel apresenta a narrativa da história da computação contada por um computador, e foca na relação entre humano-máquina a partir do dia-a-dia comum de muitas pessoas: ao ter que realizar uma atividade importante, acabam por se distrair com outras menos importantes e muitas vezes supérfluas procrastinando ao ponto de prejudicar seu desempenho no trabalho e rotina. Nessa brecha o dispositivo se insere como uma solução ao problema, oferecendo um serviço através do software digital e do objeto manipulável que se comunica com o usuário através de sons, luzes e estímulos táteis.

Figura 6 - Interação do usuário com o Prop

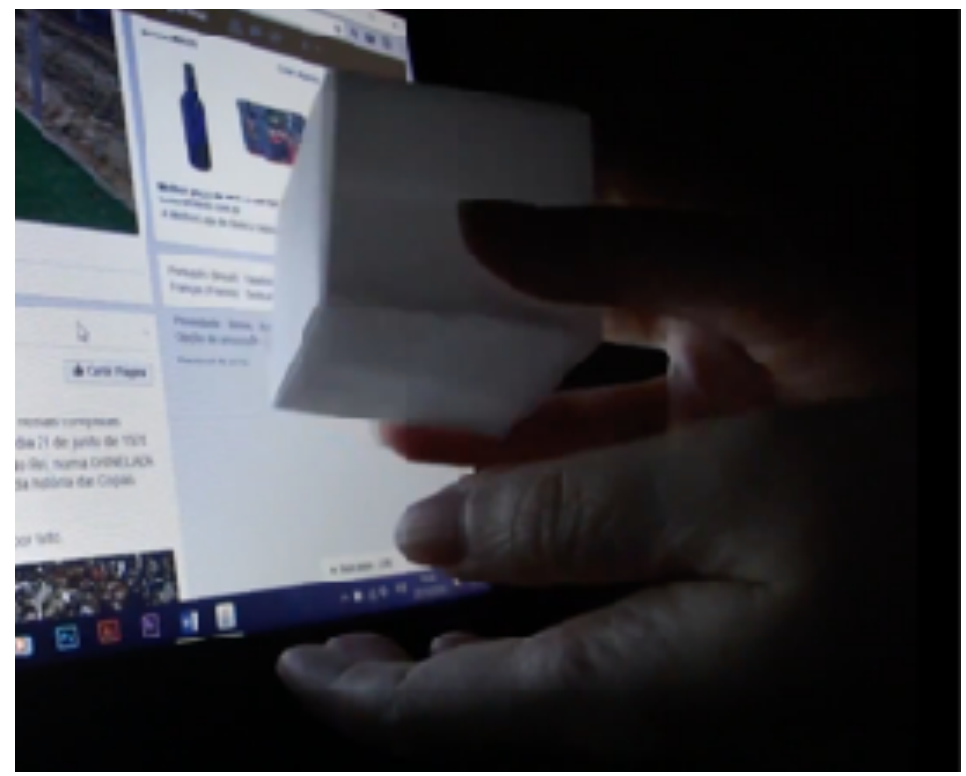

Fonte: Voxel (2017) 


\subsubsection{Abordagem}

A abordagem da ficção também assume que vivemos um período de aceleração do tempo percebido devido à grande quantidade de atividades e informações disponíveis, e sua resposta é baseada nos princípios de Design for Solitude, onde a limitação ao acesso de informações e restrição de determinadas atividades é o mecanismo pelo qual podemos experienciar uma outra percepção do tempo e, neste caso com o objetivo de concluir as atividades necessárias e "perder menos tempo" em distrações (FULLERTON, 2010), entretanto o mesmo se torna mais uma outra distração a ocupar o usuário. Entretanto, por se tratar de um projeto crítico este é justamente o objetivo da autora ao propor uma solução especulativa que gera outro problemas a serem discutidos. Mesmo que não seja exposto isso abertamente no projeto, esta fricção com a realidade é proposta.

\subsubsection{Tipo de Ficção}

Voxel pode ser considerada como uma ficção projetual pois o foco de sua proposta é na intermediação que o projeto realiza entre o usuário e suas atividades cotidianas.Também porque apresenta um prop diegético que foca na interação do usuário acerca do tema, e não serve apenas como um acessório à trama, que neste caso é a própria atividade do projeto. No espectro PPPP (DUNNY \& RABY, 2013) a obra se encontra dentro do espectro ideal entre os cones do provável e plausível, onde os meios para que o projeto se torne real já podem ser vislumbrados - já existem diversos programas assistentes e gerenciadores de tarefas que restringem 0 acesso a determinadas informações em detrimento das prioridades estabelecidas pelo usuário primeiramente - e dentro das possibilidades de ocorrer num futuro próximo, que cria uma ponte mais plausível entre a ficção e a realidade.

\subsubsection{Percepção do tempo dos personagens}

A autora cita em sua obra que conforme a mudança do computador de trabalho focado em uma tarefa por vez para o uso do computador pessoal e multitarefas, a percepção do tempo mudou para as pessoas que agora quando deveriam se sentir mais livres devido à automação de diversos procedimentos se sentem cada vez com menos tempo, devido à enorme oferta de entretenimento fornecidas o tempo todo. A quantidade de possibilidades acaba por causar a inconclusão de muitas tarefas. 0 projeto oferece uma solução que gera outros problemas e por consequência, uma reflexão sobre a proposta: ainda que seja reducionista frente à complexidade do problema da distração, sugere uma mudança de comportamento que irá demandar outro foco de atenção agora também para o cubo, agravando o problema original da procrastinação e gerando a reflexão: propor objetos e métodos de design para controlar ou evitar a procrastinação são realmente eficientes? ou apenas adicionam mais camadas de complexidade ao problema? e ainda uma questão não esclarecida: é possível e desejável solucionar este problema através do design?

\section{Conclusão}

Através da revisão bibliográfica e da análise das obras selecionadas contribuímos para ressaltar a diferença entre ficção projetual e ficção científica, no caso específico daquelas que trabalham com percepção do tempo. Pode-se observar que o gênero de ficção projetual se distingue da ficção científica pelo uso de abordagens como o Design especulativo, Temporal design e Design for Solitude, focadas nas atividades cotidianas e baseadas na interações humanas com a tecnologia especulada num cenário de futuro 
próximo. A partir da ideia que o tempo é uma construção humana, ele pode ser projetado por meio de abordagens de design como observado na proposta de Temporal Design "Family Clock" (PSCHETZ L., BASTIAN M. \& SPEED C. 2016) e do design especulativo proposto em "Voxel" (SAITO, J. H. 2017), que buscam questionar a hegemonia da padronização da temporalidade e propõe novas maneiras de percebermos o tempo. A ficção projetual é um meio pelo qual o design pode refletir sobre questões abstratas como o tempo, e desse modo contribuir ativamente propondo reflexões sobre o papel do tempo nas interações humanas e sociais.

\section{Referências}

RITTEL, Horst WJ; WEBBER, Melvin M. Dilemmas in a general theory of planning. Policy sciences, v. 4, n. 2, p. 155-169, 1973.

VAN AMSTEL, Frederick M. C. Afinal, o que é ficção projetual? (2015). Disponível em: <http://www.usabilidoido.com.br/afinal_o_que_e_ficcao_projetual.html > Acesso em 5 de abr. 2018.

BLEECKER, J. Design Fiction: A Short Essay on Design, Science, Fact and Fiction (2009). Disponível em: <http://blog.nearfuturelaboratory.com/2010/09/21/design-fiction-fromprops-to-prototypes-2010-01sj-biennial-catalog-essay/> Acesso em 5 de abr. 2018.

BLEECKER, J. Design Fiction: From props to prototypes (2010). Disponível em: <http:// drbfw5wfjlxon.cloudfront.net/writing/DesignFiction_WebEdition.pdf> Acesso em 5 de abr. 2018.

KIRBY, David. The Future is Now Diegetic Prototypes and the Role of Popular Films in Generating Real-world Technological Development (2009). Social Studies of Science 2010 40: 41

DUNNE, Anthony; RABY, Fiona. Speculative Everything: design, fiction and social dreaming. MIT Press. 2013.

WANG, Che-Wei. Tools for mindful timekeeping. 4 Devices to change our relationship to time. Massachusetts Institute of Technology. 2015.

PSCHETZ, L., BASTIAN, M., SPEED, C. (2016). Temporal design: looking at time as social coordination. Proceedings of DRS 2016, Design Research Society 50th Anniversary Conference. Brighton, UK, 27-30. 2016.

HARTMANN, Timo., GONZATTO, Rodrigo. F., MERKLE, Luiz. E. VAN AMSTEL Frederick. M. C. 2013. The ideology of the future in design fictions. Digital Creativity, 2013 Vol. 24, No. 1, 1-10, <http://dx.doi.org/10.1080/14626268.2013.772524>

Fullerton, B. (2010) Designing for solitude. interactions, 17(6), pp 6-9.

Strauss, C. F., \& Fuad-Luke, A. (2009) The slow design principles. www.slowlab.net/ CtC_SlowDesignPrinciples.pdf. (Accessed 08 November, 2015)

Hallnas, L., \& Redstrom, J. (2001) Slow technology - design for reflection. Personal Ubiquitous Comput., 5(3), pp 201-212.aito, Juliana Hiromi. desenvolveu o projeto

SAITO, Juliana. H. Voxel: Assistente digital para lidar com a procrastinação (Trabalho de Conclusão de Curso). Design Digital, PUCPR, 2016. 